\title{
A Community-Oriented Primary Care Demonstration Project: Refining Interventions for Cardiovascular Disease and Diabetes
}

\author{
Marcus Plescia, MD, MPH \\ Martha Groblewski, PbD, RD, LDN ${ }^{2}$ \\ ${ }^{1}$ Department of Family Medicine, Carolinas \\ HealthCare System, Charlotte, NC \\ ${ }^{2} \mathrm{R}$. Stuart Dickson Institute for Health \\ Studies, Carolinas HealthCare System, \\ Charlotte, NC
}

\begin{abstract}
BACKGROUND We describe a community-oriented primary care project that implemented all 5 steps of the formal model. Data are presented on cardiac risk factors, protective behaviors, health locus of control, and stage of readiness for change in an African American community. We discuss the use of these data to refine our health promotion interventions.

METHODS We undertook a cross-sectional study of self-reported health behaviors from a door-to-door household survey of a geographically-defined community. Trained community members administered the survey questionnaire, which was completed in 386 of 557 randomly sampled households (response rate 69.4\%). Qualitative discussions of survey results with 2 community groups were taped, transcribed, and analyzed for common themes.
\end{abstract}

RESULTS Compared with their counterparts, respondents who were older than 65 years $(P=.0006)$, who had hypertension $(P<.0001)$, and who had diabetes $(P=.001)$ had higher mean scores for powerful others locus of control. Rates for physical activity and low-fat diet indicators were low compared with national statistics. Most respondents reported a maintenance stage of change for exercise $(46.2 \%)$ and diet (57.5\%). Group discussions found lack of local exercise resources and high-quality grocery stores to be major barriers to health behavior change. Ministers and physicians were identified as important powerful others.

CONCLUSION This study documents low rates of physical activity and healthy dietary patterns and describes recent interventions to address environmental barriers to behavior change. The association between powerful others locus of control and specific cardiac risk factors has prompted a greater emphasis on developing faith-based interventions and renewing physician-counseling efforts. Stage of readiness for change findings have prompted strategies to disseminate existing diet and physical activity recommendations more effectively.

Ann Fam Med 2004;2:103-109. DOI: 10.1370/afm.42.

\section{INTRODUCTION}

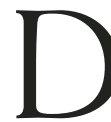
uring the last 5 years there has been a resurgence of interest in the community-oriented primary care (COPC) model in the family medicine and public health literature. ${ }^{1-6}$ The COPC approach applies public health principles in the primary care setting to define and improve the overall health of a specific population. Although exact definitions vary, the COPC process consists of several steps: (1) define a specific community of interest, (2) assess the needs and assets of this community, (3) design and implement interventions based on the community assessment, (4) evaluate and refine interventions, and (5) involve participants from the targeted community in all steps. The recent literature on COPC describes its international history, potential applications for various systems of managed care, and approaches to training health professionals in its 
use. ${ }^{1-6}$ Even though the model has played an important role in the community health center movement in the United States, there has been limited description of its successful implementation beyond the initial assessment phase.

In 1997 Carolinas Healthcare System opened a primary care center in a mid-size city in the southeastern United States. In addition to 6 full-time family physicians, the primary care center is also a satellite training site for 6 residents from our local 32 -resident family practice program. Although the practice serves any county resident, we identified a geographically defined practice community based on an existing community development effort, the Northwest Area (NWA), which contains 14 individual neighborhoods. Based on 2000 US census data, the total population of this community was estimated at 19,670, and residents were predominantly African American (89\%). Twenty-five percent of residents lived below the federal poverty level compared with $11 \%$ for the city overall.

The initial goals of the primary care center were (1) to provide culturally competent, community-based primary care services to an underserved population; (2) to address health issues beyond the 4 walls of the medical facility; and (3) to engage members of the local community in collaborative health promotion efforts. We believed a COPC process would help accomplish these goals. Over time we have organized a coalition of grass-roots community activists and representatives from local agencies that guides the planning, implementation, and evaluation of the project. An extensive community assessment documented considerable health disparities between the local community and the rest of the county. ${ }^{7}$

Two health priority areas were ascertained by the coalition, cardiovascular disease and diabetes; and health promotion pilot interventions, supported by funds from the local hospital system, were initiated to target these conditions. In 1999, the coalition received a large health disparities grant from the Centers for Disease Control and Prevention to augment efforts to target cardiovascular disease and diabetes. The resulting project focuses on training and supporting lay health advisors, who function as community catalysts to promote healthy diet patterns, increased exercise, and smoking avoidance and cessation. A full-time diabetes case manager served as the formal interface between the community-based interventions and the primary care center.

To better characterize health behaviors and further target and assist the lay health advisors' efforts, the coalition recruited community residents to conduct a second household survey in the NWA. A priority of the survey was to collect data on health locus of control and stage of readiness for change, because they were considered useful approaches to health promotion but have had less extensive application in minority communities. ${ }^{8}$ The stage of readiness for change model describes change as a continuum of stages: precontemplation, contemplation, preparation, action, maintenance, and relapse. ${ }^{9}$ Applications of the model have been documented in predominantly African American communities for smoking cessation, ${ }^{10-12}$ exercise, ${ }^{13-15}$ and dietary behavior change. ${ }^{16-18}$ The health locus of control model defines an individual's sense of control over his or her health as being directly related to his or her own beliefs and actions (internal) or the result of external factors, such as of fate or chance (chance) or the influence of other important persons (powerful others). ${ }^{19}$ The model is based on social learning theory, and there is evidence that a person's locus of control is associated with health behavior, particularly in combination with other predictive factors. ${ }^{20}$ Whereas the health locus of control model has been applied to African American communities in a variety of settings, there are fewer studies of its use in diabetes and cardiovascular disease. ${ }^{21-26}$

This article provides information about participation in protective health behaviors (physical activity and diet), health locus of control, and stage of readiness to change in an African American community. We discuss how quantitative and qualitative analyses of these data have been used to refine existing community-based health promotion interventions in our COPC project.

\section{METHODS}

\section{Sample Selection}

To generate a list of addresses specific to the NWA, we first geocoded county tax and public housing records, then abstracted the addresses that were within the defined community boundaries using Geographic Information System software (ArcView, Version 3.0). The resulting addresses were randomized, and 947 were selected. Known businesses and vacant property were eliminated $(n=297)$ leaving a sample of 650 households.

\section{Survey Design and Protocol}

The survey instrument comprised 54 closed-ended questions and took about 30 minutes to administer. Questions on demographics included age, race, sex, telephone number, and address. Most questions on the survey were taken from validated instruments. Sections of the Behavioral Risk Factor Surveillance System Questionnaire ${ }^{27}$ were used to determine smoking his- 
tory and self-reported rates ("told by a health professional you have...") for diabetes, hypertension, or high cholesterol levels. Wallston's Multidimensional Health Locus of Control Scale was used to determine health locus of control. ${ }^{16}$ Respondents used a Likert scale to rate their agreement with 6 statements that characterized each locus: internal, powerful others, and chance. Stage of readiness for change questions for exercise and healthy diet habits were adapted from an instrument developed by Booth et al. ${ }^{28}$

Specific questions for protective behaviors were created in an attempt to reflect more appropriately the diet and exercise patterns of the community and to simplify administration by surveyors. Exercise participation was measured by asking whether the respondent had participated in physical activity in the preceding week, and then asking the frequency of spending at least 15 minutes in each of 12 exercise or physical activity categories. Food consumption patterns were measured by asking respondents the number of times they ate foods during the previous day from each of 18 food group categories.

Community residents were trained to conduct the survey. Interviewers were instructed to attempt to contact each address 3 times on different days and times and to document the outcome of each attempt. Interviewers worked in pairs for safety reasons, and multiple interviews were allowed in each household to improve efficiency. Any permanent residents in the household who were 18 years or older were asked to participate. Respondents were given a small gift, valued at $\$ 5$, for their participation. Surveyors turned in completed questionnaires weekly, and verification telephone calls were made for selected households.

\section{Data Analysis}

Data were entered into an Access database (Microsoft Corp, Redmond, Wash), verified for accuracy, and converted to a SAS data set for analysis. Descriptive statistics were calculated for demographics, medical history, diet, and exercise patterns. Consumption of fruits and vegetables were used as an indicator of low-fat diet, and exercise patterns were compared with the recommendations of the US Surgeon General. Health locus of control was scored by summing the 6-item Likert scale for each of the 3 locus categories. Student $t$ tests were used separately to identify differences by sex;

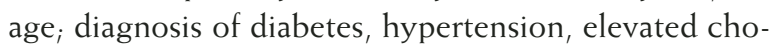
lesterol level; and smoking in locus of control scores. Statistical significance was reported at $P<.05$. Stage of readiness for change responses were regrouped into 3 categories: precontemplative-contemplative, preparation, and maintenance.

We formally presented the results from the survey to the 18 -member coalition and to a group of 15 lay health advisors, and a guided discussion format was used to determine their perceptions about the accuracy, value, and applications of the findings. The discussions were audiotaped and transcribed. The transcriptions were reviewed by the authors to identify themes that characterized the participants' reactions to the research findings, then analyzed and manually coded to identify specific text that conformed to these themes.

\section{RESULTS}

\section{Sample Characteristics}

Of the initial 650 household addresses, an additional 93 properties were found to be vacant lots or businesses by the survey teams; 70 households could not be contacted in 3 attempts, and 101 residents refused to participate in the interview. Surveys were conducted in 386 households for a response rate of $69 \%$. A total of 492 completed questionnaires were collected. The average cost per questionnaire was $\$ 61$ (\$78 per household). Forty-five respondents who did not classify themselves as African American were excluded from this analysis. Compared with the 2000 US census, the survey sample overrepresented women $(58 \%$ vs $68 \%)$ and adults older than 65 years (18\% vs $32 \%)$ and underrepresented adults aged 18 to 34 years (35\% vs $20 \%$ ), respectively. The addresses of survey respondents and those who refused to participate were geographically analyzed (data not shown). Both groups were evenly distributed among the 14 distinct neighborhoods of the target community.

\section{Health Locus of Control}

Table 1 reports mean scores for each health locus of control category measured separately by sex, age, and self-reported cardiac risk factors. Male respondents had higher mean scores than female respondents on the internal locus $(P=.02)$. Respondents 65 years old or older had higher mean scores than those younger than 65 years for the powerful others locus $(P=.0006)$. Among respondents with self-reported cardiac risk factors, those who reported a history of diabetes had higher mean scores for the powerful others locus $(P=.001)$, as did those who reported a history of hypertension $(P<.0001)$. Mean scores for respondents who reported smoking or high blood cholesterol levels did not differ for any of the health locus of control categories.

\section{Protective Behaviors}

Sixty-four (64.0) percent of respondents stated they had participated in some form of physical activity 


\section{Table 1. Health Locus of Control for Different Groups}

\begin{tabular}{|c|c|c|c|c|}
\hline \multirow[b]{2}{*}{ Characteristic } & \multirow[b]{2}{*}{ No. } & \multicolumn{3}{|c|}{ Health Locus of Control Mean Scores* (SD) } \\
\hline & & Internal & Chance & Powerful Others \\
\hline \multicolumn{5}{|l|}{ All respondents } \\
\hline Sex & 447 & $26.75(5.85)$ & $18.53(6.19)$ & $21.14(6.94)$ \\
\hline Male & 135 & $27.7^{*}(5.3)$ & $18.6(6.2)$ & $21.8(7.1)$ \\
\hline Female & 288 & $26.3^{*}(6.0)$ & $18.6(6.2)$ & $20.9(6.9)$ \\
\hline \multicolumn{5}{|l|}{ Age } \\
\hline$>65 y$ & 35 & $26.0(5.9)$ & $19.4(6.3)$ & $22.8^{*}(7.1)$ \\
\hline$<65 y$ & 292 & $27.1(5.8)$ & $18.1(6.1)$ & $20.4^{\dagger}(6.8)$ \\
\hline \multicolumn{5}{|l|}{ Diabetes } \\
\hline Yes & 57 & $25.6(6.3)$ & $19.3(5.9)$ & $24.0^{\ddagger}(6.5)$ \\
\hline No & 373 & $27.0(5.7)$ & $18.4(6.3)$ & $20.8^{\ddagger}(6.9)$ \\
\hline \multicolumn{5}{|l|}{ Hypertension } \\
\hline Yes & 190 & $26.7(6.1)$ & $18.7(6.2)$ & $22.7 \S(7.0)$ \\
\hline No & 233 & $26.8(5.6)$ & $18.4(6.2)$ & $20.0^{\S}(6.7)$ \\
\hline \multicolumn{5}{|c|}{ High cholesterol level } \\
\hline Yes & 98 & $26.7(6.1)$ & $18.6(6.0)$ & $22.0(7.1)$ \\
\hline No & 168 & $27.3(5.5)$ & $18.1(6.5)$ & $21.0(6.8)$ \\
\hline \multicolumn{5}{|l|}{ Smoking } \\
\hline Yes & 139 & $26.7(6.0)$ & $18.8(5.8)$ & $20.7(6.6)$ \\
\hline No & 284 & $26.8(5.8)$ & $18.4(6.4)$ & $21.3(7.1)$ \\
\hline \multicolumn{5}{|c|}{$\begin{array}{l}\text { *Calculated by averaging the sum of individual likert scores for the } 6 \text { questions that correspond to each } \\
\text { LOC type. }\end{array}$} \\
\hline \multicolumn{5}{|c|}{ Analyses using Student $t$ tests: } \\
\hline \multicolumn{5}{|l|}{$\begin{array}{l}{ }^{*} P=.02 . \\
\dagger P=.0006 . \\
\ddagger P=.001 . \\
\S P=.0001\end{array}$} \\
\hline
\end{tabular}

Table 2. Stage of Readiness for Change for Exercise and Diet

\begin{tabular}{|c|c|c|}
\hline Survey Items & $\begin{array}{l}\text { Stage of } \\
\text { Readiness } \\
\text { for Change }\end{array}$ & $\begin{array}{c}\text { Percent of } \\
\text { Respondents }\end{array}$ \\
\hline \multicolumn{3}{|l|}{ Exercise } \\
\hline Exercise regularly and intend to continue & Maintenance & 46.2 \\
\hline $\begin{array}{l}\text { Exercise occasionally and am not thinking of } \\
\text { doing more } \\
\text { Exercise occasionally and am thinking of } \\
\text { doing more }\end{array}$ & Preparation & 37.9 \\
\hline $\begin{array}{l}\text { Do not exercise and do not intend to start } \\
\text { Do not exercise but am thinking of starting }\end{array}$ & $\begin{array}{l}\text { Precontemplation- } \\
\text { contemplation }\end{array}$ & 15.9 \\
\hline \multicolumn{3}{|l|}{ Diet } \\
\hline Eat healthy diet regularly and intend to continue & Maintenance & 57.5 \\
\hline $\begin{array}{l}\text { Eat healthy diet occasionally and am not thinking } \\
\text { of doing more } \\
\text { Eat healthy diet occasionally and am thinking of } \\
\text { doing more }\end{array}$ & Preparation & 37.7 \\
\hline $\begin{array}{l}\text { Do not eat healthy diet and do not intend to start } \\
\text { Do not eat healthy diet but am thinking of starting }\end{array}$ & $\begin{array}{l}\text { Precontemplation- } \\
\text { contemplation }\end{array}$ & 4.8 \\
\hline
\end{tabular}

cated that they ate vegetables on the previous day, and $64.9 \%$ reported they ate fruits. Only $13.2 \%$, however, reported eating 5 or more servings of fruits and vegetables combined. Forty-five percent (44.6) of survey respondents reported they had eaten at a fast-food restaurant at least once during the past week. Most respondents $(57.5 \%)$ indicated maintenance stage of change for diet (Table 2).

\section{Community Discussions}

The lay health advisor group agreed with the data describing low levels of physical activity in this community. The coalition members were concerned that respondents were not taking credit for routine activities, such as walking to catch the bus. There were also concerns that respondents might not fully understand what constitutes a healthy diet and are often not aware of national recommendations. Important barriers to physical activity and diet change were raised. Many local neighborhoods did not have sidewalks or adequate street lighting, crime was a concern in some neighborhoods, and there were few public facilities for exercise. There were also not enough local places to purchase healthy foods, particularly fresh produce. In the words of one lay health advisor, "you have to travel to the white neighborhoods to buy good food."

The 2 groups liked the stepwise approach of the stage of readiness for change model and believed that discussion of this model was helpful for lay health advisor training.

Both groups thought the higher mean scores in the powerful others locus were accurate representations. One lay health advisor stated, "Most people in the world are not leaders, they are followers, so it is not surprising." Examples of likely powerful others were physicians, ministers, nurses, spouses, parents, and for elderly parents their children. The role of ministers was thought to be particularly important. According to one coalition mem-

ber, "Historically, when it was harder for black people during the preceding week. Thirty-five percent of all respondents reported at least moderate exercise for at least 15 minutes on 3 occasions. Most respondents $(46.2 \%)$ indicated maintenance stage of change for exercise (Table 2).

Seventy-five (75.3) percent of respondents indi- 
to get good medical treatment, the pastor was the next best thing; they would pray for you until you got better." Another said, "A lot of people will still call their minister before they call a doctor, so it is very important to involve ministers and churches in our health interventions."

\section{DISCUSSION}

In this survey of African American households, 64\% of respondents reported participation in some physical activity during the preceding week compared with $75 \%$ in national surveys of the general population. ${ }^{29,30}$ Thirteen percent ate 5 or more servings of fruits or vegetables a day compared with $19 \%$ to $23 \%$ in national surveys. ${ }^{31,32}$ Our findings are consistent with a growing number of studies reporting lower rates of exercise and healthy diet patterns for African Americans and other minority groups. ${ }^{18,29-33}$ Explanations for these disparities include different perceptions about the definition and health value of exercise and rest among African Americans, reduced knowledge about healthy dietary habits, and barriers related to availability of resources and social support. $4,18,34$

Higher mean scores for powerful others locus were found for respondents older than 65 years and for those with diabetes or hypertension when compared with their counterparts. The literature describing the use of the Multidimensional Health Locus of Control scales with African Americans documents a greater external locus of control among those with diabetes and in the elderly. ${ }^{22,23,26}$ Several studies suggest that persons with a high powerful others locus of control might be more adherent to physician or family recommendations for behavior change. ${ }^{22,26}$

Most respondents classified themselves as in the maintenance stage of change for regular exercise $(46 \%)$ or healthy diet behavior (57\%). Few respondents were in a precontemplation or contemplation stage. Previous studies of the stage of readiness for change model with mostly white study samples report much lower proportions for maintenance stage: $16 \%$ for exercise ${ }^{35}$ and $29 \%$ for diet. ${ }^{32}$ Studies of the model in African Americans report findings for exercise stage that are similar to ours. ${ }^{14,15}$ In our guided discussions, community members suggest that there might be differing definitions in this community about what constitutes regular exercise and healthy dietary patterns and that stage of change questions may need to be more specifically defined. The tendency of respondents to classify themselves at more advanced stage, however, suggests that these behaviors are perceived as desirable and that educational interventions about specific recommendations might be useful.

\section{Applications}

The participatory nature of this study is instrumental to the community-oriented approach of our health initiative. Communities are more likely to participate in interventions if they trust the data used to make decisions and feel invested in the planning process. Use of community residents to conduct this survey and extensive pilot testing of the instrument by our coalition may have contributed to our participation rate of $69 \%$, which compares favorably with other household surveys conducted in minority communities. ${ }^{36,37}$

Ongoing evaluation is a component of the COPC model, and the results of this survey have allowed us to further refine our existing interventions. Collaborative interpretation of the findings with lay health advisors and other coalition members helped bring to light unanticipated barriers to behavior change and has prompted additional interventions to increase the availability of healthy foods. A community farmers' market was started, and local restaurants and school cafeterias have been recruited to participate in healthy heart menu labeling. Physical activity barriers have been targeted by partnering with a local branch of the YMCA to provide more programs at community venues. Our findings of a strong powerful others locus of control among African Americans with diabetes or hypertension has helped our lay health advisors better understand the complexities of motivating behavior change. The likely role of ministers as powerful others has prompted increased efforts to implement educational programs and develop formal partnerships with local churches.

The most obvious benefit of the COPC project to the primary care practice has been the availability of additional resources to support counseling efforts for behavior change. These resources include local exercise classes, grocery store tours, on-site smoking cessation classes, and intensive diabetes case management. Findings from the survey were presented in a conference setting to the practice physicians, family medicine residents, and clinical support staff. The perception of physicians as powerful others and the considerable proportion of respondents who were in contemplation or action stage of change have helped renew awareness and enthusiasm to pursue behavior change counseling in the practice setting. The findings have also influenced services and initiatives offered by the practice. Smoking cessation classes are now offered on-site by project health educators using a stage of change focus. Our third-year family medicine residents, who are required to complete a longitudinal community project, are now using the PACE program, a structured, counseling intervention based on exercise stage of change, ${ }^{38}$ in a local middle school. 


\section{Limitations}

A possible limitation of this survey is the types of questions used to determine diet and exercise behavior. We used a broad measure for stage of change in which the nature, intensity, and duration of exercise or healthy diet were not specified. We also created simplified exercise and diet recall questions that were not previously validated as accurate measurements of behavior. All data were self-reported, and respondents might have been biased to give more socially desirable answers and inflate beneficial health behaviors.

Multiple interviews were allowed in each household to increase the efficiency of the survey. In a separate analysis, we randomly selected 1 respondent to represent each household and recalculated the data in Tables 1 and 2 . The results were similar and the reported statistical significance persisted. Twelve percent of households in the sample could not be contacted in 3 attempts. We believe the percentage of older adults and women is higher in our survey sample because this population was more likely to be at home. Older adults are more likely to suffer from chronic diseases, and women might be more aware of their chronic diseases because they generally have more contact with the health care system.

Eighteen percent of households refused to participate in the study. Households with less desirable health habits might have been less willing to complete a survey questionnaire, particularly if they recognized the surveyor or held the surveyor in high esteem. Although no additional data were collected about this group, respondent and refusal addresses were both evenly distributed among neighborhoods that were known to vary in their demographics and socioeconomic status.

Although not consistent with the COPC approach, $9 \%$ of the survey respondents were excluded from this analysis because they did not classify themselves as African American. Stage of change and locus of control are an important components of our interventions and evaluation plan. Members of our coalition were concerned about the applicability of existing theoretical models in minority communities and were interested in further testing these models in an exclusively African American population.

\section{CONCLUSIONS}

The purpose of this household survey was to characterize health behaviors in our focus community so we could refine our intervention strategies. As a result of the findings, we have modified existing interventions to target respondent locus of control and stage of change. Several new interventions have targeted identified barriers to behavior change. The survey also contributes to what we have learned from the COPC process. A detailed discussion of our experience will be written as the project matures, but several key points have emerged: (1) Community assessment activities should move from needs-based analysis to understanding community capacity for change. In addition to stage of behavior change and locus of control, behavior models, such as self efficacy and health beliefs, should be explored. (2) Participatory approaches to data collection and analysis might be methodologically challenging, but such challenges are offset by improved participation rates, insight, and interpretations that might not be readily evident to outside observers and by more widespread acceptance and dissemination of findings by grassroots community activists. (3) To be effective, practice-based behavior modification counseling must be combined with community-based interventions that address barriers, use local resources, and raise community awareness about important health issues.

To read commentaries or to post a response to this article, see it online at http://www.annfammed.org/cgi/content/full/2/2/103.

Key words: Primary health care; stage of readiness for change; transtheoretical model; internal-external control; African Americans; exercise; diet; community-oriented primary care.

Funding support: This study was supported by a grant from the Centers for Disease Control and Prevention, cooperative agreement number U50/ cCU417322.

Acknowledgement: We would like to acknowledge the community leaders and activists in the northwest area of Charlotte, NC, who helped make this project successful.

\section{References}

1. Mullan F, Epstein L. Community-oriented primary care: new relevance in a changing world. Am J Pub Health. 2002;92:1748-1755.

2. Baker NJ, Harper PG, Reif CJ. Use of clinical indicators to evaluate COPC projects. J Am Board Fam Pract. 2002;15:355-360.

3. Longlett SK, Kruse JE, Wesley RM. Community oriented primary care: historical perspective. J Am Board Fam Pract. 2001;14:54-63.

4. Longlett SK, Kruse JE, Wesley RM. Community oriented primary care: critical assessment and implications for resident education. J Am Board Fam Pract. 2001;14:141-147.

5. Pathman DE, Steiner BD, Williams E, Riggins T. The four community dimensions of primary care practice. J Fam Pract. 1998;46:293.

6. Rhyne R, Cushman SB, Kantrowitz M. An introduction to community-oriented primary care. In: Rhyne R, Bogue R, Kukulka G, Fulmer $\mathrm{H}$, eds. Community-Oriented Primary Care: Health Care for the 21st Century. Washington, DC: American Public Health Association; 1998.

7. Plescia M, Koontz S, Laurent S. Community assessment in a vertically integrated health care system. Am J Pub Health. 2001;91:811-814.

8. Ashing-Giwa K. Health behavior change models and their sociocultural relevance for breast cancer screening in African American women. Women Health. 1999;28:53-71

9. Prochaska JO, DiClemente CC. Stage and processes of self change of smoking: toward an integrative model. J Consult Clin Psychol. $1983 ; 51: 390-395$. 
10. Voorhees C, Stillman FA, Swark RT, et al. Heart, body and soul: impact of church-based smoking cessation interventions on readiness to quit. Prev Med. 1996;25:277-285.

11. Schorling J. The stages of change of rural African American smokers. Am J Prev Med. 1995;11:170-177.

12. Johnson Jl, Fava JL, Velicer WF, Monroe AD, Emmons K. Testing stage effect in an ethnically diverse sample. Addict Behav. 2002;27: 605-617.

13. Suminski RR, Petosa R. Stages of change among ethnically diverse college students. J Am Coll Health. 2002; 51:26-31

14. Walcott-McQuigg JA, Prohaska TR. Factors influencing participation of African-American elders in exercise behavior. Pub Health Nurs. 2001;18:194-203.

15. Bull FC, Eyler AA, King AC, Brownson RC. Stage of readiness to exercise in ethnically diverse women: a US survey. Med Sci Sports Exerc. 2001;1147-1156.

16. Hargreaves MK, Schlundt DG, Buchowski MS, Rossi SR, Rossi JS Stages of change and the intake of dietary fat in African-American women: improving stage assignments using the Eating Styles Questionnaire. J Am Diet Assoc. 1999;99:1392-1399.

17. Auslander W, Haire-Joshu D, Houston C, Rhee C, Williams JH. A controlled evaluation of staging dietary patterns to reduce the risk of diabetes in African-American women. Diabetes Care. 2002;25:809. 814.

18. Campbell MK, Symons M, Denmark-Wahnefried W, et al. Stages of change and psychosocial correlates of fruit and vegetable consump tion among rural African-American church members. Am J Health Prom. 1998;12:185-191.

19. Wallston KA, Wallston BS, DeVellis R. Development of the multidimensional health locus of control (MHLC) scales. Health Educ Monog. 1978;6:160-170.

20. Oberle K. A decade of research in locus of control: what have we learned? J Adv Nurs. 1991;16:800-806.

21. Morisky DE, Bowler MH, Finlay JS. An educational and behavioral approach toward increasing patient activation in hypertension management. J Community Health. 1982;7:171-182.

22. Bell RA, Summerson JH, Konen JC. Racial differences in psychosocial variables among adults with non-insulin-dependent diabetes mellitus. Behav Med. 1995;21:69-73.

23. Hayes RP, Bernard AM, Slocum W, et al. Diabetes in urban African Amercians: assessment of diabetes-specific locus of control in patients with type 2 diabetes. Diabetes Educ. 2000;26:121-128.

24. Hamm VP, Bazargan M, Barbre AR. Life-style and cardiovascular health among urban Black elderly. J Appl Gerontol. 1993;12:155-169.
25. Weaver GD, Gary LE. Correlates of health-related behaviors in older African-American adults: implications for health promotion. Fam Commun Health. 1996;19:43-57.

26. Gillibrand W, Flynn M. Forced externalization of control in people with diabetes: a qualitative exploratory study. J Adv Nurs. 2001;34: 501-510.

27. Behavioral Risk Factor Surveillance Survey. Centers for Disease Control and Prevention. Available at: http://www.2.cdc.gov/needphp/brtss.

28. Booth ML, Macaskill P, Owen N, Oldenburg B, Marcus BH, Bauman A. Population prevalence and correlates of stages of change in physical activity. Health Educ Q. 1993;20:431-440.

29. US Department of Health and Human Services. Physical Activity and Health: A Report of the Surgeon General. Washington, DC: National Center for Chronic Disease Prevention and Health Promotion. US Department of Health and Human Services; 1996.

30. United States Department of Health and Human Services. Centers for Disease Control and Prevention. Physical activity trends-United States, 1990-1998. MMWR. 2001;50:166-169.

31. Subar AF, Heimendinger J, Patterson BH, Krebs-Smith SM, Pivonka E, Kessler R. Fruit and vegetable intake in the United States: the baseline survey of the Five A Day for Better Health program. Am J Health Prom. 1995;9:352-360.

32. Laforge R, Greene G, Prochaska J. Psychosocial factors influencing low fruit and vegetable consumption. J Behav Med. 1994;17:361-374.

33. US Department of Health and Human Services. Public Health Service, Office of the Surgeon General. The Surgeon General's Call to Action to Prevent and Decrease Overweight and Obesity. Washington, DC: US Department of Health and Human Services; 2001.

34. Airhihenbuwa CO, Kumanyika S, Agurs TD, Lowe A. Perceptions and beliefs about exercise, rest, and health among African-Americans. Am J Health Prom. 195;9:426-429.

35. Marcus BH, Banspach SW, Lefebvre RC, Rossi JS, Carleton RA, Abrams DB. Using the stages of change model to increase the adoption of physical activity among community participants. Am J Health Prom. 1992;6:424-429.

36. Torres MI. Assessing health in an urban neighborhood: community process, data results and implications for practice. J Comm Health. $1998 ; 23: 211-226$

37. Taylor BR, Haley D. The use of household surveys in communityoriented primary care health needs assessments. Fam Med. 1996;28: 415-421.

38. Patrick K, Sallis JF, Prochaska JJ, et al. A multicomponent program for nutrition and physical activity change in primary care: PACE + for adolescents. Arch Pediatr Adolesc Med. 2001;155:940-946. 